\title{
Promoter methylation profile of GSTP1 and RASSF 1A in benign hyperplasia and metastatic prostate cancer patients in a Kashmiri population
}

\author{
NIDDA SYEED ${ }^{1}$, A. SYED SAMEER ${ }^{1}$, ARIF HAMID $^{2}$, ZAFAR A. SHAH $^{1}$, \\ DIL AFROZE $^{1}$, ROOHI RASOOL ${ }^{1}$ and MUSHTAQ A. SIDDIQI ${ }^{1}$ \\ Departments of ${ }^{1}$ Immunology and Molecular Medicine, and ${ }^{2}$ Urology, \\ Sher-i-Kashmir Institute of Medical Sciences, Soura, India
}

Received June 8, 2010; Accepted July 26, 2010

DOI: $10.3892 / \mathrm{mmr} .2010 .348$

\begin{abstract}
Promoter hypermethylation is a marginal approach to inactivating tumor suppressor genes in cancer. DNA hypermethylation is a well-recognized epigenetic malfunction observed in several malignancies, most predominantly in prostate cancer. Aberrant DNA methylation patterns are considered to be the earliest somatic genome changes in prostate cancer. The function of promoter hypermethylation in malignant transformation of the prostate has been widely studied, from its presence in benign hyperplasia (BHP) to development and to the advanced stages of tumor formation. In the present study, we examined the promoter hypermethylation status of the glutathione S-transferase P1 (GSTP1) and RASSF1A genes in 45 BHP samples, 50 proven prostate tumor samples and 80 normal samples. Hypermethylated GSTP1 was found in 29/50 (58.0\%) prostate carcinoma cases and 12/45 (26.6\%) BHP cases. The RASSF 1A gene was methylated in $17 / 50$ (34.0\%) prostate cancer samples and 7/45 (15.5\%) BHP samples. On the basis of these findings, we propose that the epigenetic regulation of the GSTP1 and RASSF1A genes through promoter hypermethylation may play a crucial role in the progression of prostate cancer, and has probable involvement in BHP.
\end{abstract}

\section{Introduction}

Prostate cancer is a most important health concern in North America and Europe (1). Worldwide, it is the second most common non-cutaneous cancer in men, accounting for $10 \%$ of male cancers (2). Prostate cancer is the second leading cause of cancer-related death among men in North America and Western/Northern Europe (3). A major challenge is in distinguishing between clinically benign and aggressive

Correspondence to: Dr Mushtaq A. Siddiqi, Department of Immunology and Molecular Medicine, Sher-i-Kashmir Institute of Medical Sciences, Soura, Srinagar, Kashmir 190011, India

E-mail:vc.tmuk@gmail.com

Key words: GSTP1, RASFF1A, prostate cancer, benign hyperplasia prostate cancers. In spite of increasing research, the genetic mechanisms underlying the development and progression of prostate cancer are not well known. Cancer development and metastasis are multistep processes that involve the inactivation of tumor suppressor genes. Once the tumor has metastasized, the long-term prognosis is poor, as no curative therapy is available (4).

DNA methylation of $\mathrm{CpG}$ sites in the promoter region of genes is a frequent epigenetic event involved in the pathogenesis of many human cancers $(5,6)$. Epigenetic alterations, especially DNA hypermethylation, are thought to play an important role in the down-regulation of genes that have been shown to cause prostate cancer. In addition to classic genetic aberrations, epigenetic alterations have emerged as a main driving force in the molecular pathology of prostate cancer (7). DNA methylation provides an alternate pathway to gene deletion or tumor-suppressor gene mutations. Aberrant promoter methylation has been reported for several genes in a number of malignancies, and the variety of genes involved suggests that specific tumors may have their own distinct pattern of methylation (8). The focus of the present study was on the DNA methylation status of the RASSF 1A and GSTP1 genes and their role in the deregulation of apoptosis in prostate cancer.

The RAS family of proto-oncogenes plays a significant role in the signal transduction pathways involved in cell proliferation and survival, where it interacts with other regulatory circuits of cell growth and death. Recently, a new gene encoding RAS-binding proteins, RASSF 1A, has been identified as having a crucial lung and breast cancer deletion region at $3 \mathrm{p} 21.3(9,10)$. The RASSF $1 A$ gene has been reported to be silenced by aberrant hypermethylation of promoter $A$ in a large fraction of lung $(9,11,12)$, breast $(11,12)$ and gastric (13) tumors.

Glutathione S-transferase P1 (GSTP1) is a protector gene whose silencing by hypermethylation leads to DNA damage and the initiation of cancer $(14,15)$. Hypermethylation is a frequent event in prostate carcinoma, and by far the most frequent genomic alteration to be detected is hypermethylation of the GSTP1 promoter region (49\%) (16). It has been confirmed that methylation of the GSTP1 promoter region 
Table I. Effect of GSTP1 and RASSF1A hypermethylation pattern in prostate cancer patients from Kashmir Valley.

\begin{tabular}{|c|c|c|c|c|c|c|c|c|c|}
\hline Variable & $\begin{array}{c}\text { PCA } \\
\text { No. }(\%)\end{array}$ & $\begin{array}{c}G S T P 1 \\
\text { methylation }\end{array}$ & OR & $95 \% \mathrm{CI}$ & $\mathrm{P}$-value & $\begin{array}{c}\text { RASSF 1A } \\
\text { methylation }\end{array}$ & OR & $95 \% \mathrm{CI}$ & P-value \\
\hline Age & & & 2.94 & $0.24-34.85$ & 0.56 & & 0.23 & $0.01-2.79$ & 0.54 \\
\hline$>50$ & 47 (94) & 28 & & & & 15 & & & \\
\hline$\leq 50$ & $3(6)$ & 1 & & & & 2 & & & \\
\hline Dwelling & & & 0.26 & $0.06-1.15$ & 0.09 & & 0.25 & $0.06-0.98$ & 0.07 \\
\hline Rural & $38(76)$ & 17 & & & & 10 & & & \\
\hline Urban & $12(24)$ & 9 & & & & 7 & & & \\
\hline Smoking status & & & 2.28 & $0.52-9.92$ & 0.31 & & 5.07 & $1.22-21.06$ & 0.03 \\
\hline No & $11(22)$ & 8 & & & & 7 & & & \\
\hline Yes & 39 (78) & 21 & & & & 10 & & & \\
\hline Pesticide exposure & & & 0.23 & $0.07-0.80$ & 0.02 & & 1.77 & $0.53-5.8$ & 0.37 \\
\hline Low & $19(38)$ & 7 & & & & 8 & & & \\
\hline High & $31(62)$ & 22 & & & & 9 & & & \\
\hline PSA level & & & 0.65 & $0.17-2.40$ & 0.73 & & 0.12 & $0.01-1.06$ & 0.03 \\
\hline Low (4-8) & $12(24)$ & 6 & & & & 1 & & & \\
\hline $\operatorname{High}(8-13)$ & $38(76)$ & 23 & & & & 16 & & & \\
\hline Tumor stage & & & 0.23 & $0.07-0.77$ & 0.02 & & 1.36 & $0.41-4.45$ & 0.76 \\
\hline $\mathrm{I}+\mathrm{II}(\mathrm{a}+\mathrm{b})$ & $21(42)$ & 8 & & & & 8 & & & \\
\hline III $(a+b)+$ IV & $29(58)$ & 21 & & & & 9 & & & \\
\hline $\begin{array}{l}\text { Histopathological } \\
\text { tumor grade }\end{array}$ & & & 6.56 & $1.88-22.87$ & 0.003 & & 1.52 & $0.45-5.11$ & 0.55 \\
\hline WD+MD & $27(54)$ & 21 & & & & 11 & & & \\
\hline PD & $23(26)$ & 8 & & & & 6 & & & \\
\hline
\end{tabular}

WD, well differentiated; MD, moderately differentiated; PD, poorly differentiated.

results in the loss of GSTP1 expression in prostate cancer cells $(17,18)$. Currently in the US, the methylation status of GSTP1 is being examined in clinical trials as a promising diagnostic marker of prostate carcinoma $(19,20)$.

Here, we present evidence that the RASSF1A and GSTP1 genes are inactivated in prostatic cells during the pathogenesis of prostate carcinoma as a consequence of $\mathrm{CpG}$ island DNA hypermethylation, and that cells with inactivated RASSF $1 A$ and GSTP1 genes may be selected during human prostate carcinogenesis. Hypermethylation promotes carcinogenesis in prostate cancer by affecting cell cycle control, hormonal response, cell adhesion and cell architecture (21).

\section{Materials and methods}

Patients and tumor tissue procurement. Acohort of 95 randomly selected male patients admitted to the Department of Urology, Sher-i-Kashmir Institute of Medical Sciences, were included in the study. The patients underwent histopathological diagnosis of prostate cancer in the Department of Histopathology of our institution. Fifty prostate tumor samples and 45 benign hyperplasia (BHP) samples were collected. Samples from 80 healthy males over 50 years of age served as the controls. We also obtained prostate sextant biopsy specimens from 10 patients with elevated levels of serum PSA. Prostate samples consisting of tumor tissues and adjacent normal tissue were collected. Only histopathologically confirmed tumors were included in the study. The study was approved by the Ethical Committee of the Sher-i-Kashmir Institute of Medical Sciences.

DNA isolation. Genomic DNA was extracted from the tissue and peripheral blood samples of the breast cancer patients using a DNA Extraction kit (Qiagen, USA). The quality of the resulting genomic DNA was stringently assessed using low percentage agarose gel electrophoresis and UV spectrophotometry.

Methylation-specific polymerase chain reaction for RASSF1A and GSTP1. Bisulphite treatment converts unmethylated but not methylated cytosines to uracil. During the subsequent amplification step, uracil is converted to thymidine, producing sequences between methylated and unmethylated DNA. Genomic DNA isolated from tumors and adjacent normal tissues using the protocol described above was bisulphite modified using a commercial kit (Methylation Direct kit, Zymoresearch) according to the manufacturer's instructions. The modified DNA was amplified using methylation-specific primers $(12,22)$. Bisulfite-modified DNA (3 $\mu \mathrm{l}$ ) was used in the PCR mix, which contained 1X PCR buffer, $200 \mu \mathrm{mol} / \mathrm{l}$ dNTP, 2 units Amp gold Taq DNA poly- 
Table II. Effect of GSTP1 and RASSF 1A hypermethylation pattern in benign hyperplasia patients from Kashmir Valley.

\begin{tabular}{|c|c|c|c|c|c|c|c|c|c|}
\hline Variable & $\begin{array}{c}\text { BHP } \\
\text { No. }(\%)\end{array}$ & $\begin{array}{c}\text { GSTP1 } \\
\text { methylation }\end{array}$ & OR & $95 \% \mathrm{CI}$ & P-value & $\begin{array}{c}\text { RASSF1A } \\
\text { methylation }\end{array}$ & OR & $95 \% \mathrm{CI}$ & P-value \\
\hline Age & & & 0.11 & $0.01-0.73$ & 0.02 & & 0.33 & $0.02-4.27$ & 0.40 \\
\hline$>50$ & $42(93.3)$ & 8 & & & & 6 & & & \\
\hline$\leq 50$ & $3(6.60)$ & 4 & & & & 1 & & & \\
\hline Dwelling & & & 0.52 & $0.13-2.08$ & 0.47 & & 0.54 & $0.10-2.83$ & 0.65 \\
\hline Rural & $31(68.8)$ & 7 & & & & 4 & & & \\
\hline Urban & $14(35.7)$ & 5 & & & & 3 & & & \\
\hline Smoking status & & & 0.67 & $0.16-2.70$ & 0.73 & & 0.20 & $0.02-1.87$ & 0.21 \\
\hline No & $18(14.8)$ & 4 & & & & 1 & & & \\
\hline Yes & $27(44.4)$ & 8 & & & & 6 & & & \\
\hline Pesticide exposure & & & 0.40 & $0.19-2.74$ & 0.30 & & 0.55 & $0.09-3.20$ & 0.68 \\
\hline Low & $18(23.8)$ & 3 & & & & 2 & & & \\
\hline High & $27(29.1)$ & 9 & & & & 5 & & & \\
\hline PSA level & & & 0.12 & $0.02-0.56$ & 0.00 & & 0.07 & $0.00-0.71$ & 0.01 \\
\hline Low (4-8) & $27(11.1)$ & 3 & & & & 1 & & & \\
\hline High (8-12) & $18(50.0)$ & 9 & & & & 6 & & & \\
\hline Tumor stage & & & 0.32 & $0.08-1.30$ & 0.17 & & 2.26 & $0.39-13.06$ & 0.43 \\
\hline II $(a+b)$ & $24(16.6)$ & 4 & & & & 5 & & & \\
\hline III $(a+b)+$ IV & $21(38.0)$ & 8 & & & & 2 & & & \\
\hline $\begin{array}{l}\text { Histopathological } \\
\text { tumor grade }\end{array}$ & & & 1.48 & $0.39-5.60$ & 0.73 & & 7.41 & $0.81-67.6$ & 0.09 \\
\hline WD+MD & $23(30.4)$ & 7 & & & & 5 & & & \\
\hline PD & $22(22.7)$ & 5 & & & & 2 & & & \\
\hline
\end{tabular}

WD, well differentiated; MD, moderately differentiated; PD, poorly differentiated.

merase and $0.4 \mu \mathrm{M}$ of the primer. The mixture was amplified using the specific reaction conditions. The PCR products (10 $\mu \mathrm{l}$ ) were loaded onto $6 \%$ denaturing polyacyrlamide gels, stained using ethidium bromide and visualized under a UV illuminator.

\section{Results}

GSTP1 promoter methylation in prostate carcinoma and benign hyperplasia. Initially, we analyzed GSTP1 promoter methylation in 50 prostate cancer samples from patients with clinically localized prostate carcinoma who underwent radical prostatectomy, and in 45 patients with histologically documented BHP who underwent a transurethral resection of the prostate. Using methylation-specific PCR, MSP analysis revealed methylated GSTP1 in 29/50 (58.0\%) prostate carcinoma cases. Additionally, 12/45 (26.6\%) patients with BHP showed some GSTP1 methylation (Tables I and II).

RASSF1A promoter methylation in prostate carcinoma and BHP. RASSF1A promoter region hypermethylation was found in $17 / 50(34.0 \%)$ prostate cancer samples. Among the 45 BHP samples analyzed, $7 / 45$ (15.5\%) samples exhibited RASSF1A methylation. Although microdissection was performed for each prostate cancer sample, unmethylated
PCR product was detected in many of the tumor samples, which may have been due to the presence of remaining nonmalignant cells. RASSF1A methylation was also detected in 4/50 normal tissue DNA samples whose corresponding tumor was also methylated, indicating that silencing of the RASSF $1 A$ promoter might be an early event in certain cases of prostate cancer. Hypermethylation was observed in all of the histopathologically proven cancer patients. Using statistical analysis, methylation was examined with regard to the clinicopathological parameters of the cancer patients (Tables I and II).

\section{Discussion}

DNA hypermethylation is a well recognized epigenetic malfunction observed in several malignancies, most predominantly in prostate cancer (23). Several characteristics of DNA hypermethylation make it advantageous as a cancer biomarker. Tumorigenesis is a multi-step process and hypermethylation is hypothesized to be an early event in the development and progression of prostate cancer (21). DNA methylation is of great importance in human cancer, and researchers have focused on regions of the genome that might have functional significance resulting from the extinction of gene activity. The methylational status of numerous genes has already been 
studied in various types of cancer (8). Hypermethylation promotes tumorigenesis in prostate cancer by affecting cell adhesion and cell architecture, cell cycle control and hormonal response. In the present study, we studied the GSTPl gene, which is a DNA repair gene, and the RASSF1A gene, which is involved in signal transduction.

GSTP1 is a protector gene involved in intracellular detoxification. Silencing of this gene by promoter hypermethylation leads to DNA damage and the initiation of cancer. The most common somatic genome alteration observed during prostate cancer development is hypermethylation of the regulatory region of the promoter of the k-class GSTP1 gene (24-26). In the present study, we found GSTP1 promoter hypermethylation in $58 \%$ of prostate cancer samples and $26 \%$ in BHPs, indicating the possible presence of pre-malignant lesions. The usefulness of GSTP1 hypermethylation is that it may serve as an early detection biomarker. This contributes to the evidence that suggests that GSTP1, together with other genes shown to be methylated in prostate cancer, may be a powerful diagnostic and prognostic biomarker $(8,27)$.

RASSF 1A is a potential tumor suppressor that interacts with $\mathrm{Cdc} 20$, an activator of the anaphase-promoting complex, to inhibit complex activity and prevent mitotic progression. RASSF 1A has been studied in many tumors in which methylation correlates with reduced expression (28). Methylation of RASSF 1A has been reported at similar frequencies in prostate cancer and also in prostatic BHP, an age-related non-cancerous enlargement of the prostate (29-31). Epigenetic inactivation of RASSF $1 A$ is observed in 53-71\% of solid tumors and epithelial cancers, including prostate cancer $(32,33)$. In our study, the RASSF1A promoter was methylated in $34 \%$ of prostate cancer cases and $15 \%$ of BHPs. These findings specify a potential role of RASSF1A in the diagnosis, pathogenesis and spread of prostate cancer. The results also demonstrate that RASSF $1 A$ is not only silenced in prostate cancer, but also in certain BHPs. Detection of the epigenetic silencing of RASSF 1A in BHP represents early carcinogenesis, as has been shown by others (9). As previously reported, RASSF $1 A$ acts as a guardian of mitosis (34); therefore, the occurrence of hypermethylation at the RASSF1A gene locus might also be a sign of clinicallyrelated, but is still considered BHP.

We found a lower percentage of hypermethylation than most studies, although a similar percentage has been found by one other study (35). The results also indicated a statistically significant correlation between GSTP1 and RASSF1A gene hypermethylation status and the clinical epidemiological characteristics of the prostate cancer patients, as show in Table I.

A significant association was found between the promoter hypermethylation of GSTP1 in prostate cancer and hyperplastic tissue with pesticide exposure, suggesting a potential role of pesticides in the development and progression of both. A decisive study has been carried out on pesticide exposure in farmers, indicating that farmers are more likely to die of diseases including heart disease, as well as cancer of the lung, bladder, liver, prostate, colon, esophagus, rectum and kidney, and all of the above combined (36). As most of our patients were from the rural areas of Kashmir Valley where the sole source of income is farming and very little is known about the hazards of pesticides, a significant association between prostate cancer and pesticide exposure exists in this group, as well as in the BHP patients, who are more vulnerable to the development of prostate cancer.

We found a significant association between GSTP1 promoter hypermethylation with tumor grade (I and II) and histopathological stage, where the presence of hypermethylation in the primary tumor indicates its role in the early development of prostate cancer, and thereafter its metastasis indicates its role in tumor progression.

We also found a significant correlation between pre-operative serum levels and the promoter methylation of GSTP1 in BHP samples, as reported in a previous study (33). This demonstrated that $24 \%$ of men who underwent a prostate biopsy due to abnormal (increased) serologic PSA, ultrasonographic, or clinical findings later presented prostate cancer in subsequent biopsies.

Furthermore, we found a significant relation between GSTP1 promoter hypermethylation and advanced age in BHP patients. As previously mentioned, hypermethylation of GSTP1 appears to be an early genetic alteration in prostate cancer (37). Recent evidence indicates that the methylation of $\mathrm{CpG}$ islands present in the promoter regions of certain genes in normal-appearing tissues/BHPs may be associated with aging $(32,35)$. GSTP1 hypermethylation found in such patients postbiopsy may be useful for the identification of patients who are at potential risk of carrying the malignancy despite a negative biopsy, and may aid in determining whether or not a repeat biopsy in the event of a negative initial result is necessary.

A significant association between RASSF1A promoter methylation and smoking status in the prostate cancer patients was found. Additionally, a significant correlation between RASSF1A promoter hypermethylation and high pre-operative serum PSA was found. The high PSA groups had a significantly greater frequency of RASSFIA methylation in prostate tumor and BHP samples.

Based on these findings, we propose that the epigenetic regulation of the RASSFIA gene through promoter hypermethylation may play an important role in the progression of prostate cancer, and may also play a role in the development of BHP into prostate cancer.

An essential feature of our study was that we found the methylation status of both GSTP1 and RASSF1A to be elevated in certain common cancer samples. We suggest that the hypermethylation of GSTP1 is an early event in prostate carcinoma (30), and that RASSFIA may be involved in the progression of cancer in these cases. This analysis indicates that not only are the RASSF1A and GSTP1 genes hypermethylated in prostate cancer, but that promoter methylation of these genes may actually start in the benign prostate, and may then progress to cancer.

Even if RASSF1A or GSTP1 methylation alone is not responsible for prostate cancer development, it is possible that the combination of the two may contribute to tumor formation and progression, as these genes are involved in crucial molecular pathways of carcinogenesis, such as DNA repair, cell cycle regulation and signal transduction. The high rate of occurrence of methylation at the promoter region of these genes strongly suggests that it plays an important role in epigenetic alteration in prostate tumorigenesis. However, it is worth noting the differences in methylation levels of these genes between neoplastic and benign tissues. We conclude 
that a few more genes, along with these two, may be included in a diagnostic test panel for the diagnosis and prognosis of prostate cancer as well as of BHPs.

\section{Acknowledgements}

The authors gratefully acknowledge the Indian Council for Medical Research (ICMR) for providing funds for this study. We also acknowledge the statistical help of Tariq A. Jan of the Department of Statistics, University of Kashmir, and thank the pathologists at the Department of Pathology for the histopathological assessment of the tumor tissues.

\section{References}

1. Jemal A, Tiwari RC and Murray T: Cancer statistics. CA Cancer J Clin 54: 8-292, 2004.

2. Parkin DM, Bray F, Ferlay $\mathbf{J}$ and Pisani P: Global cancer statistics. CA: Cancer J Clin 55: 74-108, 2002.

3. Hughes C, Murphy A, Martin C, Sheils O and O'Leary J: Molecular pathology of prostate cancer. J Clin Pathol 58: 673-684, 2005.

4. Johansson JE, Holmberg L, Johansson S, Bergstrom R and Adami HO: Fifteen-year survival in prostate cancer: a prospective, population-based study in Sweden. JAMA 277: 467-471, 1997.

5. Baylin SB, Herman JG, Graff JR, Vertino PM and Issa JP: Alterations in DNA methylation: a fundamental aspect of neoplasia. Adv Cancer Res 72: 141-196, 1998.

6. Costello JF, Fruhwald MC, Smiraglia DJ, et al: Aberrant CpG-island methylation has non-random and tumour-typespecific patterns. Nat Genet 24: 132-138, 2000

7. Perry AS, Foley R, Woodson K and Lawler M: The emerging roles of DNA methylation in the clinical management of prostate cancer. Endocr Relat Cancer 13: 357-377, 2006.

8. Esteller M, Corn PG, Baylin SB and Herman JG: A gene hypermethylation profile of human cancer. Cancer Res 61: 3225-3229, 2001.

9. Dammann R, Li C, Yoon JH, Chin PL, Bates S and Pfeifer GP: Epigenetic inactivation of RAS association domain family protein from the lung tumor suppressor locus 3p21.3. Nat Genet 25: 315-319, 2000

10. Lerman MI and Minna JD: The 630-kb lung cancer homozygous deletion region on human chromosome 3p21.3: identification and evaluation of the resident candidate tumor suppressor genes. The International Lung Cancer Chromosome 3p21.3 Tumor Suppressor Gene Consortium. Cancer Res 60: 6116-6133, 2000.

11. Agathanggelou A, Honorio S, Macartney DP, et al: Methylation associated inactivation of RASSF1A from region 3p21.3 in lung, breast and ovarian tumors. Oncogene 20: 1509-1518, 2001.

12. Burbee DG, Forgacs E, Zochbauer-Muller S, et al: Epigenetic inactivation of RASSF1A in lung and breast cancers and malignant phenotype suppression. J Natl Cancer Inst 93: 691-699, 2001.

13. Byun DS, Lee MG, Chae KS, Ryu BG and Chi SG: Frequent epigenetic inactivation of RASSF1A by aberrant promoter hypermethylation in human gastric adenocarcinoma. Cancer Res 61: 7034-7038, 2001.

14. Singal R, Ferdinand L, Reis IM and Schlesselman JJ: Methylation of multiple genes in prostate cancer and the relationship with clinicopathological features of disease. Oncol Rep 12: 631-637, 2004.

15. Nelson CP, Kidd LC, Sauvageot J, Isaacs WB, De Marzo AM and Groopman JD: Protection against 2-hydroxyamino-1methyl-6-phenylimidazo[4,5-b]pyridine cytotoxicity and DNA adduct formation in human prostate by glutathione $\mathrm{S}$-transferase P1. Cancer Res 61: 103-109, 2001.

16. Lee WH, Morton RA, Epstein JI, Brooks JD, Campbell PA, Bova GS, Hsieh WS, Isaacs WB and Nelson WG: Methylation of regulatory sequences near the pi-class glutathione S-transferase gene accompanies human prostatic carcinogenesis. Proc Nat Acad Sci 91: 11733-11737, 1994.

17. Singal R, van Wert J and Bashambu M: Cytosine methylation represses glutathione S-transferase P1 (GSTP1) gene expression in human prostate cancer cells. Cancer Res 61: 4820-4826, 2001
18. Lin X, Tascilar M, Lee WH, et al: GSTP1 CpG island hypermethylation is responsible for the absence of GSTP1 expression in human prostate cancer cells. Am J Pathol 159: 1815-1826, 2001.

19. Goessl C, Muller M, Heicappell R, Krause H, Straub B, Schrader $\mathrm{M}$ and Miller K: Epigenetic marker. Urology 58: 335-338, 2001.

20. Cairns P, Esteller M, Herman JG, Schoenberg M, Jeronimo C, Sanchez-Cespedes M, Chow NH, Grasso M, Wu L, Westra WB and Sidransky D : Molecular detection of prostate cancer in urine by GSTP1 hypermethylation. Clin Cancer Res 7: 2727-2730, 2001.

21. Li LC, Okino ST and Dahiya R: DNA methylation in prostate cancer. Biochim Biophys Acta 1704: 87-102, 2004.

22. Esteller M, Corn PG, Drena JM, Gabrielson E, Baylin SB and Herman JG: Inactivation of glutathione 5-transferase PI gene by promoter hypermethylation in human neoplasia. Cancer Res 58: 4515-4518, 1998

23. Li LC, Carroll PR and Dahiya R: Epigenetic changes in prostate cancer: implication for diagnosis and treatment. J Natl Cancer Inst 97: 103-115, 2005.

24. Hoque MO, Topaloglu O and Begum S: Quantitative methylation-specific polymerase chain reaction gene patterns in urine sediment distinguish pro state cancer patients from control subjects. J Clin Oncol 23: 6569-6575, 2005.

25. Henrique $\mathrm{R}$ and Jeronimo C: Molecular detection of prostate cancer: a role for GSTP1 hypermethylation. Eur Urol 46: 660-669, 2004

26. Harden SV, Guo Z, Epstein JI and Sidransky D: Quantitative GSTP1 methylation clearly distinguishes benign prostatic tissue and limited prostate adenocarcinoma. J Urol 169: 1138-1142, 2003.

27. Bastian PJ, Ellinger J, Wellmann A, Wernert N, Heukamp LC, Muller SC and von Ruecker A: Diagnostic and prognostic information in prostate cancer with the help of a small set of hypermethylated gene loci. Clin Cancer Res 11: 4097-4106, 2005.

28. Shivakumar L, Minna J, Sakamaki T, Pestell R and White MA: The RASSF1A tumor suppressor blocks cell cycle progression and inhibits cyclin D1 accumulation. Mol Cell Biol 22: 4309-4318, 2002.

29. Chu DC, Chuang CK, Fu JB, Huang HS, Tseng CP and Sun CF: The use of real-time quantitative polymerase chain reaction to detect hypermethylation of the $\mathrm{CpG}$ islands in the promoter region flanking the GSTP1 gene to diagnose prostate cancer. J Urol 167: 1854-1858, 2002.

30. Jeronimo C, Henrique R, Hoque MO, Ribeiro FR, Oliveira J, Fonseca D, Teixeira MR, Lopes C and Sidransky D: Quantitative RARbeta2 hypermethylation: a promising prostate cancer marker. Clin Cancer Res 10: 4010-4014, 2004.

31. Jeronimo C, Henrique R, Hoque MO, Mambo E, Ribeiro FR, Varzim G, Oliveira J, Teixeira MR, Lopes C and Sidransky D: A quantitative promoter methylation profile of prostate cancer. Clin Cancer Res 10: 8472-8478, 2004.

32. Ahuja N, Li Q, Mohan AL, Baylin SB and Issa JP: Aging, DNA methylation in colorectal mucosa and cancer. Cancer Res 58: 5489-5494, 1998.

33. Keetch DW, Catalona WJ and Smith DS: Serial prostatic biopsies in men with persistently elevated serum prostate specific antigen values. J Urol 151: 1571-1574, 1994.

34. Song MS, Song SJ and Ayad NG: The tumour suppressor RASSF1A regulates mitosis by inhibiting the APC-Cdc20 complex. Nat Cell Biol 6: 129-137, 2004.

35. Maruyama R, Toyooka S, Toyooka KO, Virmani AK, ZöchbauerMüller S, Farinas AJ, Minna JD, McConnell J, Frenkel EP and Gazdar AF: Aberrant promoter methylation profile of prostate cancers and its relationship to clinicopathological features. Clin Cancer Res 8: 514-519, 2002

36. Blair A and Zahm SH: Agricultural exposures and cancer. Environ Health Perspect 103: 205-208, 1995.

37. Brooks JD, Weinstein M, Lin X, Sun Y, Pin SS and Bova GS: CPG island methylation changes near the GSTP1 gene in prostatic intraepithelial neoplasia. Cancer Epidemiol Biomark Prev 7: 531-536, 1998.

38. Toyota $\mathrm{M}$ and Issa JP: $\mathrm{CpG}$ island methylator phenotypes in aging and cancer. Semin Cancer Biol 9: 349-357, 1999. 